\title{
THE PUBLIC WELL-BEING-(continued)
}

\section{WAR ON DISEASE. \\ International Conference in London.}

THE Commission which had met informally on the invitation of the British Government in July 1919 to discuss certain questions of international concern in connection with health, was invited by the Council of the League of Nations to constitute a conference by adding to its members a small number of international health experts, with an official of the League as secretary. This Conference was to prepare for submission to the Council proposals concerning the constitution of a permanent body to whom the Council might refer for advice, and, if necessary, for action on all health questions within the scope of the League. The Conference, constituted in accordance with the wish expressed by the Council, had its first session in London on April 13, and concluded its business last Saturday. Viscount Astor was the chairman, and the Conference consisted of delegates from France, Great Britain, Italy, Japan, the United States, the League of Red Cross Societies, and the Office. International d'Hygiène Publique.

The scheme agreed upon for submission to the Council of the League of Nations is broadly on the lines of the International Labour Office, which mean $_{\mathrm{S}}$ that there will be a permanent international health organisation as part of the League, with its secretariat, its executive committee, and a general committee acting in some degree like an international health parliament. The executive committee will meet at least four times a year, and the general committee at least once a year. The main functions of this permanent organisation will be to advise the League in matters affecting health; to bring administrative health authorities in different countries into close relationship with each other; to organise means of rapid interchange of information on matters whereon immediate precautions against disease may be required, as, for example, in epidemics; and to simplify methods for acting rapidly on such information where it affects more than one country; to provide a ready organisation for securing or revising necessary international agreements; and, broadly, to confer and co-operate with the League of Red: Cross Societies and other health organisations. It is proposed also that it should advise, when requested, authorised voluntary organisations in health matters of international concern. In regard to. measures for the protection of the worker against disease, sickness and injury arising out of his employment which fall within the provinice of the: International Labour Organisation, the International Health Organisation will co-operate with, and assist the Labour Organisation. The International Labour Organisation on its part will act in consultation with the International Health Organisation in regard to all health matters.

The permanent organisation will incorporate the Bureau and Office International d'Hygiène Publique, which up to the present has been the official international health organisation. The Bureau, which will be the Secretariat of the Organisation, will include a medical secretary, and its headquarters will be at the seat of the League.

Lord Astor, in an interview, emphasised the importance of the League's initiative, and the hope of: far-reaching results not only in preventing and combating the spread of disease, but also in improving: the general welfare of all countries and in establishing better understanding. Such work as the iriternational care of health and of conditions of labour would do much in assisting to make the. League an influential and living organism.

The representatives of Great Britain at the Con-ference were Sir George Newman, Dr. G. S. Buchanan, and Dr. Steegmann (Technical Adviser). Surgeon-General Rupert Blue was the United States delegate, and the League of Red Cross: Societies was represented by General Sir David: Henderson and Solonel R. P. Strong, U.S.A. (Technical advisor). A member of the Secretariat of the League of Nations, Dame Rachel Crowdy, R.R.C., acted as secretary.

\section{Homes for Mothers.}

A MUnicipal home for mothers will shortly be opened in Birmingham. The work of the health officials shows that there is always a considerable number of mothers who, owing to poor physique, a bad confinement, or adverse domestic circumstances, cannot take up again without grave danger to their health their household duties, and whose circumstances do not permit the rest which would enable them to recuperate. There is danger to themselves from their low state of health, and it reacts also on the welfare of the baby. The municipality has acquired an estate which will give an opportunity of developing the work of meeting these needs in more favourable conditions than hitherto. The estate is pleasantly situated. T Wenty-four to thirty mothers will be the guests-paying guests - of the municipality at one time. It is found that in the majority of cases a fortnight's change is sufficient to fit the mother to resume her domestic duties. The guests will be asked to contribute a portion of the cost of their maintenance according to their means, but the scale. will be adjusted so that no case which can benefit from a: stay at the home will be deterred from going there by the cost. Everything possible will be done to enable mothers. to escape from those permanent disabilities which so often follow too early resumption of domestic duties after confinement, and to go back to their homes strong and well,. with healthy babies.

The foregoing plans relate to married mothers. An interesting example of what is being done in another. centre for unmarried mothers is to be found in Manchester, at Ennismore, Pendleton. In an appeal for funds for this establishment, it is explained that it now contains twelve mothers and twelve babies. The mothers do the work of the home themselves, under the supervision of the matron and a trained nurse. Two of the mothers work in the nursery, one in the laundry, one in the kitchen,. and one serves as housemaid. They receive wages for the: 